\title{
Mycobacterium llatzerense sp. nov., a facultatively autotrophic, hydrogen-oxidizing bacterium isolated from haemodialysis water
}

Correspondence

Jorge Lalucat

jlalucat@uib.es

\author{
Margarita Gomila, ${ }^{1}$ Antonio Ramirez, ${ }^{2}$ Joan Gascó ${ }^{3}$ and Jorge Lalucat ${ }^{1}$ \\ ${ }^{1}$ Àrea Microbiologia, Departament de Biologia, Universitat de les Illes Balears, and Institut \\ Mediterrani d'Estudis Avançats (CSIC-UIB), 07122 Palma de Mallorca, Illes Balears, Spain \\ ${ }^{2}$ Servei de Microbiologia, Hospital Universitari Son Dureta, 07014 Palma de Mallorca, Illes Balears, \\ Spain \\ ${ }^{3}$ Unitat de Nefrologia (Departament Mèdic), Hospital Son Llàtzer, 07198 Palma de Mallorca, Illes \\ Balears, Spain
}

\begin{abstract}
Six mycobacterial isolates from haemodialysis water, conforming a homogeneous phylogenetic group in a previous multigenic analysis, were classified taxonomically. Physiological and biochemical characterization, as well as DNA-DNA hybridizations, demonstrated that the isolates were facultatively autotrophic, aerobic and hydrogen-oxidizing bacteria, representing a novel species in the rapid growing Mycobacterium group, for which the name Mycobacterium llatzerense sp. nov. is proposed. The type strain is MG13 ${ }^{\top}$ (=CECT $7273^{\top}=$ CCUG $\left.54744^{\top}\right)$.
\end{abstract}

Many species of the genus Mycobacterium are widely distributed in the environment, and include organisms that might be pathogenic to humans and animals. When isolated from samples taken from patients, these organisms are referred to as non-tuberculous mycobacteria or simply environmental mycobacteria. Environmental mycobacteria are ubiquitous, and are found in many ecosystems, such as water, dust or soil. In hospitals, they occur mainly in aquatic environments and, because of their resistance to many disinfectants, they can survive and might be the cause of nosocomial outbreaks. In addition, they have been implicated increasingly in human diseases, including nosocomial infections, pulmonary and disseminated diseases in immunocompromised patients, and in a variety of other diseases. In the majority of these occurrences, water was proposed as a possible common vehicle of transmission. At the time of writing, the genus Mycobacterium comprised 130 species with validly published names (http://www.bacterio.cict.fr), 45 of which (35\%) have been described recently, since 2000, in fact. This high increase over the last few years may be due to the introduction of molecular techniques in taxonomy and the identification of isolates from environmental sources and clinical specimens.

Mycobacteria that are able to grow autotrophically with hydrogen have been reported several times in the literature (Eberhardt, 1965; Aragno \& Schlegel, 1992) and were

The GenBank/EMBL/DDBJ accession numbers for the $16 \mathrm{~S}$ rRNA gene nucleotide sequences determined in this study for the novel strains are AJ746069-AJ746073 and AJ746075 and that for Mycobacterium mucogenicum CCUG 47451 is AM902750. classified as members of the species Mycobacterium fortuitum (Lukins and Foster, 1963), Mycobacterium gordonae (Bojalil et al., 1962), Mycobacterium marinum (Eberhardt, 1965) and Mycobacterium phlei, or as other Mycobacterium species that are no longer recognized in bacterial taxonomy, namely 'Mycobacterium album' or 'Mycobacterium citreum' (Eberhardt, 1965), but have not been classified using modern taxonomical tools. The ability to grow aerobically with carbon monoxide as the only carbon and energy source has also been described recently for many mycobacteria (Park et al., 2003).

In a previous environmental study, 60 isolates from a total of 203 obtained using R2A medium (Reasoner \& Geldreich, 1985) from different sampling points of a water distribution system in a haemodialysis unit in the Hospital Son Llàtzer (Mallorca, Spain) were affiliated to the genus Mycobacterium (Gomila et al., 2005), by employing partial 16S rRNA gene sequencing. The use of this phylogenetic marker has not been effective in the discrimination of strains at species level, making a phylogenetic multigenic sequence analysis approach necessary, using seven housekeeping genes (16S rRNA gene, ITS1, gyrB, hsp65, recA, $r p o B$ and $\operatorname{sod} A)$. A multilocus sequence typing approach was performed on 20 isolates, leading to the differentiation of five distinct groups (Gomila et al., 2007). On the basis of the genetic analysis, DNA-DNA hybridization and the phenotypic characteristics, including biochemical tests and antimicrobial susceptibility analysis, we concluded that six of the 20 isolates made up a homogeneous group of strains representing a putative novel species. One of these isolates, designated strain $\mathrm{MG}^{\mathrm{T}}{ }^{\mathrm{T}}$, was deposited in the Spanish 
Type Culture Collection and in the Culture Collection of the University of Göteborg with accession numbers CECT $7273^{\mathrm{T}}$ and CCUG $54744^{\mathrm{T}}$.

In the multigenic sequence analysis, we demonstrated that the six mycobacterial isolates studied $\left(\mathrm{MG} 12, \mathrm{MG}^{\mathrm{T}}\right.$, MG14, MG15, MG16 and MG18) were closely related phylogenetically to Mycobacterium aubagnense CCUG 50186 ${ }^{T}$, Mycobacterium mucogenicum CCUG 47451 and Mycobacterium phocaicum CCUG $50185^{\mathrm{T}}$ at consensus distances around 94.2, 94.5 and $94.8 \%$, respectively (Gomila et al., 2007). All strains were included in the phenotypic and biochemical analysis. Strains were routinely cultured in R2A medium incubated for 3-4 days at $30{ }^{\circ} \mathrm{C}$.

Colonies on R2A agar medium at $30{ }^{\circ} \mathrm{C}$ incubated for 5 days were 1-2 $\mathrm{mm}$ in width, yellowish, circular, convex and with entire margins. Cells were irregular rods, positive using Ziehl-Neelsen staining, and frequently showed a typical $\mathrm{V}$ form when dividing. The ability to grow at various temperatures $\left(22,30,37\right.$ and $\left.45^{\circ} \mathrm{C}\right)$ on Löwenstein-Jensen slants was determined, as well as the ability to grow on blood agar and Mueller-Hinton agar, on MacConkey agar without crystal violet and on LöwensteinJensen supplemented with $5 \% \mathrm{NaCl}$. Hydrolysis of Tween 80 and urea was also tested, as well as catalase activity at $68{ }^{\circ} \mathrm{C}$, and a semi-quantitative catalase test was also performed, according to procedures described by Lutz (1992). The novel isolates were tested for aerobic autotrophic growth with hydrogen in mineral medium as described by Aragno \& Schlegel (1992) at different $\mathrm{O}_{2}$ partial pressures. All isolates were able to grow auto- trophically in the presence of hydrogen and $\mathrm{CO}_{2}$, but not when a mixture of carbon monoxide and $\mathrm{O}_{2}$ was given in the gas phase. Additional biochemical tests were performed by inoculating API Coryne and API 20E (bioMérieux) strips according to the manufacturer's instructions, with an incubation time of 3 days at $30{ }^{\circ} \mathrm{C}$. The results are shown in Table 1. Characteristics that differed from those of other closely related species included the ability to hydrolyse Tween 80 and gelatin, nitrate reduction, citrate utilization and hydrolysis of urea. All strains grew well at 22 and $30{ }^{\circ} \mathrm{C}$, but no growth was observed at $37^{\circ} \mathrm{C}$. Pyrrolidonyl arylamidase, $\alpha$-glucosidase and catalase tests were negative, and alkaline phosphatase was positive. Phenotypically, $M$. aubagnense was the most closely related species.

Antibiotic susceptibility testing was also performed (Table 2). Mycobacterial suspensions of the isolates were prepared by emulsifying colonies grown on R2A plates in $5 \mathrm{ml}$ sterile distilled water, to achieve a density equal to a 1.0 McFarland turbidity standard by visual examination. The suspensions were mixed vigorously on a vortex mixer for $20 \mathrm{~s}$ and then inoculated on the entire surface of a Mueller-Hinton agar plate. The minimum inhibitory concentrations (MICs) of amoxicillin/clavulanate, cefotaxime, ceftazidime, ciprofloxacin, clarithromycin, clindamycin, cotrimoxazole, erythromycin, imipenem, linezolid, meropenem, metronidazole, minocycline, penicillin, teicoplanin, tobramycin and vancomycin, were determined by incubation with the respective E-test (AB Biodisk, Sweden) at $30{ }^{\circ} \mathrm{C}$ for 3 days. The MIC of the antimicrobial agents tested was determined according to the breakpoints recommended by the NCCLS (NCCLS, 2002, 2003) and

Table 1. Differential phenotypic characteristics of the novel isolates (Mycobacterium llatzerense sp. nov.) and phylogenetically related rapidly growing mycobacteria

Strains: 1, M. llatzerense MG12; 2, M. llatzerense MG13 ${ }^{\mathrm{T}}$; 3, M. llatzerense MG15; 4, M. llatzerense MG16; 5, M. llatzerense MG18; 6, M. llatzerense MG14; 7, M. aubagnense CCUG 50186 ${ }^{\mathrm{T}}$; 8, M. mucogenicum CCUG 47451; 9, M. phocaicum CCUG 50185 $5^{\mathrm{T}}$. + , Positive; -, negative; w, weak growth; ND, no data available. Results given in parentheses were taken from Adékambi et al. (2006). All strains are positive for growth at 22 and $30{ }^{\circ} \mathrm{C}$, acetoin production (Voges-Proskauer) and $\beta$-glucosidase (aesculin hydrolysis) and negative for growth at $45{ }^{\circ} \mathrm{C}$ and in $5 \%(\mathrm{w} / \mathrm{v}) \mathrm{NaCl}$, pigmentation, semiquantitative catalase, $\beta$-galactosidase, growth on MacConkey agar without crystal violet, arginine dihydrolase, lysine decarboxylase, ornithine decarboxylase, indole production, tryptophan deaminase, $\mathrm{H}_{2} \mathrm{~S}$ production, pyrrolidonyl arylamidase, $\beta$-glucuronidase, $N$ acetyl- $\beta$-glucosaminidase and fermentation/oxidation of amygdalin, arabinose, glucose, glycogen, inositol, maltose, mannitol, melibiose, ribose, sucrose, sorbitol and xylose.

\begin{tabular}{|c|c|c|c|c|c|c|c|c|c|}
\hline Characteristic & 1 & 2 & 3 & 4 & 5 & 6 & 7 & 8 & 9 \\
\hline Growth at $37^{\circ} \mathrm{C}$ & - & - & - & - & - & - & + & + & + \\
\hline \multicolumn{10}{|l|}{ Hydrolysis of: } \\
\hline Tween 80 ( 5 and 10 days) & + & + & + & + & + & + & + & - & - \\
\hline Urea & - & - & - & - & - & - & $+(-)$ & - & - \\
\hline Catalase at $68{ }^{\circ} \mathrm{C}$ & - & - & - & - & - & - & $-(+)$ & - & $-(+)$ \\
\hline Nitrate reduction, citrate utilization & - & - & - & - & - & - & - & - & + \\
\hline Gelatinase & - & - & - & - & - & - & $+(-)$ & - & - \\
\hline Growth with $\mathrm{H}_{2}$ & + & + & + & + & + & + & ND & - & ND \\
\hline Pyrazinamidase & - & - & - & - & - & - & - & $\mathrm{w}$ & $-(+)$ \\
\hline Alkaline phosphatase & + & + & + & + & + & + & + & - & + \\
\hline$\alpha$-Glucosidase & - & - & - & - & - & - & - & - & $+(-)$ \\
\hline
\end{tabular}


Table 2. Antimicrobial susceptibility of the novel isolates (Mycobacterium llatzerense sp. nov.) and closely related Mycobacterium species

Strains: 1, M. llatzerense MG12; 2, M. llatzerense MG13 ${ }^{\mathrm{T}}$; 3, M. llatzerense MG15; 4, M. llatzerense MG16; 5, M. llatzerense MG18; 6, M. llatzerense MG14; 7, M. aubagnense CCUG 50186 ${ }^{\mathrm{T}}$; 8, M. mucogenicum CCUG 47451; 9, M. phocaicum CCUG 50185 ${ }^{\mathrm{T}}$. Values are MIC ( $\mu \mathrm{g}$ ml ${ }^{-1}$ ). AMC, Amoxicillin/clavulanate. Data in parentheses were taken from Adékambi et al. (2006).

\begin{tabular}{|c|c|c|c|c|c|c|c|c|c|}
\hline Antimicrobial & 1 & 2 & 3 & 4 & 5 & 6 & 7 & 8 & 9 \\
\hline Amikacin & 0.125 & 0.125 & 0.125 & 0.125 & 0.064 & 0.125 & $1(3)$ & 1.5 & $1(1.5)$ \\
\hline Ceftazidime & $>256$ & $>256$ & $>256$ & $>256$ & $>256$ & $>256$ & $>256$ & $>256$ & $>256$ \\
\hline Ciprofloxacin & $<0.004$ & $<0.004$ & $<0.004$ & $<0.004$ & $<0.004$ & 0.012 & $0.064(0.125)$ & 1 & 0.50 \\
\hline Clarithromycin & $<0.016$ & $<0.016$ & $<0.016$ & $<0.016$ & $<0.016$ & $<0.016$ & $0.064(0.125)$ & 0.032 & 0.064 \\
\hline Erythromycin & 0.25 & 0.25 & 0.125 & 0.125 & 0.25 & 0.5 & $0.5(1)$ & 1 & $2(3)$ \\
\hline Imipenem & 1 & 0.5 & 1 & 1 & 0.5 & 1 & $1(0.75)$ & 1 & 0.50 \\
\hline Linezolid & 0.25 & 0.5 & 0.125 & 0.125 & 0.5 & 0.25 & 0.125 & 1 & 12 \\
\hline Meropenem & 1 & 0.5 & 1 & 1 & 1 & 1 & $>32$ & 12 & 2 \\
\hline Metronidazole & $>256$ & $>256$ & $>256$ & $>256$ & $>256$ & $>256$ & $>256$ & $>256$ & $>256$ \\
\hline Vancomycin & $32^{*}$ & $64^{*}$ & $32^{*}$ & $32^{*}$ & $64^{*}$ & $128^{*}$ & $>256$ & 32 & $>256$ \\
\hline
\end{tabular}

${ }^{\star}$ Indicates the presence of trailing.

those proposed by Brown-Elliott \& Wallace (2002). The novel isolates were susceptible to ciprofloxacin, clarithromycin and minocycline, differentiating them from the other species studied. All were resistant to ceftazidime, cefotaxime, metronidazole and penicillin.

DNA of the six phenotypically identical isolates was extracted from colonies grown on R2A medium for 3 or 4 days at $30{ }^{\circ} \mathrm{C}$, as described previously (Gomila et al., 2005). Amplification and sequencing of the complete $16 \mathrm{~S}$ rRNA genes was performed using primers $16 \mathrm{~F} 27,16 \mathrm{~F} 357$, $16 \mathrm{~F} 610$ and 16R1492, according to the procedure described by Gomila et al. (2005). The gene sequences were aligned with closely related sequences retrieved from the BLAST nucleotide sequence database. The alignment was done using a hierarchical method for multiple alignments, implemented in the program CLUSTAL_X (Thompson et al., 1997). Sequences that were aligned automatically were checked manually. Evolutionary distances, derived from sequence-pair dissimilarities [Jukes and Cantor correction (Jukes \& Cantor, 1969)] were calculated using the program DNADIST included in the Phylogenetic Inference Package [PHYLIP version 3.5c (Felsenstein, 1989)]. A phylogenetic tree was constructed using the neighbour-joining distance method (Fig. 1). Bootstrap analysis (based on 1000 replicates) was done using the PHYLIP package; only values greater than 700 are indicated. Topologies of the trees were visualized with the program TreeView (Page, 1996). The $16 \mathrm{~S}$ rRNA gene sequences of the novel Mycobacterium strains were identical and had a similarity of $98.7 \%$ (18 bp differences in $1380 \mathrm{bp}$ ) with the sequence of $M$. aubagnense CCUG $50186^{\mathrm{T}}$, and around $98 \%$ with the other type strains in the same phylogenetic branch: $98.6 \%$ similarity (20 bp differences in 1380 bp) with M. mucogenicum CCUG 47451 and $98.2 \%$ (24 bp differences in 1380 bp) with M. phocaicum CCUG $50185^{\mathrm{T}}$.

A multilocus sequence typing study including ITS1, gyrB, hsp65, recA, rpoB and sodA genes was undertaken previously (Gomila et al., 2007). The gyrB and recA genes allowed a better discrimination of the novel isolates from closely related type strains. The gyrB gene of the novel strains showed $87 \%$ similarity with $M$. aubagnense CCUG $50186^{\mathrm{T}}, 89 \%$ with $M$. phocaicum CCUG $50185^{\mathrm{T}}$ and $90 \%$ with $M$. mucogenicum CCUG 47451. recA gene similarities were $92.8 \%$ with $M$. aubagnense CCUG $50186^{\mathrm{T}}$ and $94 \%$ with M. mucogenicum CCUG 47451 and M. phocaicum CCUG $50185^{\mathrm{T}}$. sodA gene similarities were $94.7 \%$ with $M$. aubagnense CCUG $50186^{\mathrm{T}}$ and $97 \%$ with the other two closely related strains, and similarities for the $h s p 65$ gene were around $95 \%$ between the novel strains and the closely related strains. $r p o B$ gene similarities were $95 \%$ with $M$. aubagnense CCUG $50186^{\mathrm{T}}$ and $96 \%$ with the other two closely related strains, M. mucogenicum CCUG 47451 and M. phocaicum CCUG $50185^{\mathrm{T}}$.

In several bacterial species, a correlation between multigene analysis and levels of DNA-DNA relatedness have been 


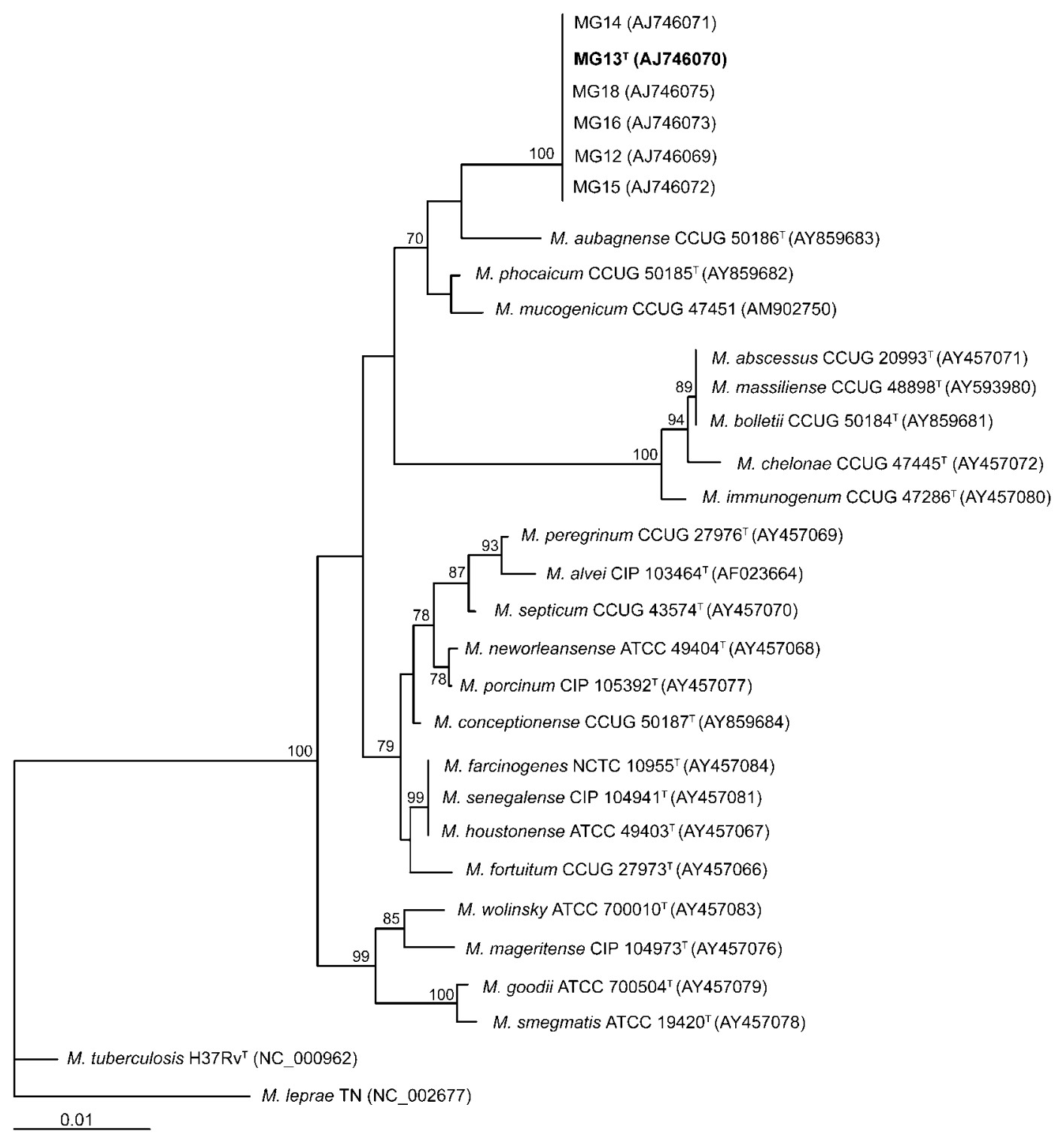

Fig. 1. Phylogenetic tree based on $16 S$ rRNA gene sequences of the novel strains and other related, rapidly growing mycobacterial species as determined by comparison of over 1380 aligned bases. The tree was constructed using the neighbour-joining method, following distance analysis calculated by using the method of Jukes \& Cantor (1969). The topology of the tree was visualized with the program TreeView (Page, 1996). Bootstrap values greater than 700 (based on 1000 replications) are indicated as percentages at branch points. GenBank accession numbers are given in parentheses. Bar, 0.01 nucleotide substitutions per site.

demonstrated and their study has been encouraged by Stackebrandt et al. (2002). Therefore, total DNA was isolated from cells grown in $11 \mathrm{R} 2 \mathrm{~A}$ broth using a method modified according to Marmur (1961). Briefly, to achieve better lysis, pelleted cells were boiled for $20 \mathrm{~min}$ and sonicated (10 cycles of $20 \mathrm{~s}$ at 22 microns amplitude and cooling for $5 \mathrm{~s}$ ). DNADNA hybridizations were performed in duplicate using a non-radioactive method, as described by Ziemke et al. (1998). Reference DNAs of strains M. aubagnense CCUG $50186^{\mathrm{T}}, M$. bolletii CCUG $50184^{\mathrm{T}}$ and strain $\mathrm{MG}^{\mathrm{T}}{ }^{\mathrm{T}}$ were double-labelled with DIG-11-dUTP and biotin-16-dUTP using a Nick Translation kit (Boehringer Mannheim). Labelled DNA was hybridized with DNA of strains MG12, M. mucogenicum CCUG 47451 and M. phocaicum CCUG $50185^{\mathrm{T}}$. The level of relatedness of strains $\mathrm{MG}^{\mathrm{T}}{ }^{\mathrm{T}}$ and MG12 with other type strains of the genus Mycobacterium tested was less than $50 \%$, in all cases, and was $100 \%$ between strains $\mathrm{MG}^{\mathrm{T}}{ }^{\mathrm{T}}$ and $\mathrm{MG12}$, indicating that a new genomic group could be delineated in the genus.

Based on the phylogenetic and phenotypic analyses, we conclude that the isolates MG12, MG13 ${ }^{\mathrm{T}}$, MG14, MG15, 
MG16 and MG18 represent a novel species in the genus Mycobacterium, for which the name Mycobacterium llatzerense is proposed.

\section{Description of Mycobacterium llatzerense sp. nov.}

Mycobacterium llatzerense (1.lat.ze.ren'se. N.L. neut. adj. llatzerense pertaining to Hospital Son Llàtzer, the hospital where the strains were isolated).

Acid-fast, Gram-positive bacilli, irregular, with frequent V forms during cell division. Aerobic, non-fermentative. Colonies are non-pigmented and grow on R2A medium, $5 \%$ sheep blood agar, Middlebrook $7 \mathrm{H10}$ agar and Löwenstein-Jensen slants, in 3-4 days, at temperatures between 22 and $30{ }^{\circ} \mathrm{C}$. No growth is observed at $37^{\circ} \mathrm{C}$ or $45{ }^{\circ} \mathrm{C}$, nor with $5 \%(\mathrm{w} / \mathrm{v}) \mathrm{NaCl}$. Negative for catalase activity (catalase at $68{ }^{\circ} \mathrm{C}$ and semiquantitative), and positive for hydrolysis of Tween 80 within 5 days. Cannot hydrolyse urea. Negative for citrate utilization, $\mathrm{H}_{2} \mathrm{~S}$ production, gelatinase, nitrate reduction, pyrazinamidase, pyrrolidonyl arylamidase, $\beta$-glucuronidase, $\alpha$ glucosidase, $N$-acetyl- $\beta$-glucosaminidase, $\beta$-galactosidase, arginine dihydrolase, lysine decarboxylase, ornithine decarboxylase and tryptophan deaminase, and positive for alkaline phosphatase, aesculin hydrolysis and acetoin production (Voges-Proskauer). Susceptible to ciprofloxacin, clarithromycin and minocycline and resistant to cefotaxime, ceftazidime, metronidazole and penicillin.

The type strain, $\mathrm{MG}^{\mathrm{T}}{ }^{\mathrm{T}}\left(=\mathrm{CECT} 7273^{\mathrm{T}}=\right.$ CCUG $\left.54744^{\mathrm{T}}\right)$, was isolated from a pure water distribution system of a haemodialysis unit in the Hospital Son Llàtzer, Mallorca, Spain.

\section{Acknowledgements}

This work was supported in part by the CICYT (Spain) and FEDER grant REN2002-04035-CO3-01 and by the I Plà Balear de Recerca I Desenvolupament Tecnològic de les Illes Balears. M. G. was the recipient of a predoctoral fellowship from the Spanish Ministerio de Educación y Ciencia. We are grateful to the CCUG for providing type strains of Mycobacterium. We also thank Professor Ortwin Meyer from the Bayreuth University and Professor Botho Bowien from the University of Göttingen, for their help in testing autotrophic growth on $\mathrm{H}_{2}$ and $\mathrm{CO}$.

\section{References}

Adékambi, T., Berger, P., Raoult, D. \& Drancourt, M. (2006). rpoB gene sequence-based characterization of emerging non-tuberculous mycobacteria with descriptions of Mycobacterium bolletii sp. nov., Mycobacterium phocaicum sp. nov. and Mycobacterium aubagnense sp. nov. Int J Syst Evol Microbiol 56, 133-143.

Aragno, M. \& Schlegel, H. G. (1992). The mesophilic hydrogenoxidizing (Knallgas) bacteria. In The Prokaryotes, 2nd edn, vol. 1, pp 344-384. Edited by A. Balows, H. G. Trüper, M. Dworkin, W. Harder \& K. H. Schleifer. Berlin: Springer.

Bojalil, L. F., Cerbon, J. \& Trujillo, A. (1962). Adansonian classification of mycobacteria. J Gen Microbiol 28, 333-346.

Brown-Elliott, B. A. \& Wallace, R. J., Jr (2002). Clinical and taxonomic status of pathogenic nonpigmented or late-pigmenting rapidly growing mycobacteria. Clin Microbiol Rev 15, 716-746.

Eberhardt, U. (1965). Die Anreicherung von Knallgasbakterien. In Anreicherungskultur und Mutantenauslese, pp 155-178. Edited by $\mathrm{H}$. G. Schlegel. Stuttgart: Gustav Fischer (in German).

Felsenstein, J. (1989). PHYLIP - phylogeny inference package (version 3.2). Cladistics 5, 164-166.

Gomila, M., Gascó, J., Busquets, A., Gil, J., Bernabeu, R., Buades, J. M. \& Lalucat, J. (2005). Identification of culturable bacteria present in haemodialysis water and fluid. FEMS Microbiol Ecol 52, 101-114.

Gomila, M., Ramirez, A. \& Lalucat, J. (2007). Diversity of environmental Mycobacterium isolates from hemodialysis water as shown by a multigene sequencing approach. Appl Environ Microbiol 73, 3787-3797.

Jukes, T. H. \& Cantor, C. R. (1969). Evolution of protein molecules. In Mammalian Protein Metabolism, vol. 3, pp. 21-132. Edited by H. N. Munro. New York: Academic Press.

Lukins, H. B. \& Foster, J. W. (1963). Utilization of hydrocarbons and hydrogen by mycobacteria. $Z$ Allg Mikrobiol 3, 251-264.

Lutz, B. (1992). Identification tests for mycobacteria. In Clinical Microbiology Procedures Handbook, pp. 3.12.1-3.12.27. Edited by H. D. Isenberg. Washington, DC: American Society for Microbiology.

Marmur, J. (1961). A procedure for the isolation of deoxyribonucleic acid from microorganisms. J Mol Biol 3, 208-218.

NCCLS (2002). Performance standards for antimicrobial susceptibility testing. Twelfth Informational Supplement, M100-S12. Wayne, PA: NCCLS.

NCCLS (2003). Susceptibility testing of Mycobacteria, Nocardia, and other aerobic actinomycetes. Approved standard M24-A. Wayne, PA: NCCLS.

Page, R. D. M. (1996). TreeView: an application to display phylogenetic trees on personal computers. Comput Appl Biosci 12, 357-358.

Park, S. W., Hwang, E. H., Park, H., Kim, J. A., Heo, J., Lee, K. H., Song, T., Kim, E., Ro, Y. T. \& other authors (2003). Growth of mycobacteria on carbon monoxide and methanol. J Bacteriol 185, 142-147.

Reasoner, D. J. \& Geldreich, E. E. (1985). A new medium for the enumeration and subculture of bacteria from potable water. Appl Environ Microbiol 49, 1-7.

Stackebrandt, E., Frederiksen, W., Garrity, G. M., Grimont, P. A. D., Kämpfer, P., Maiden, M. C. J., Nesme, X., Rosselló-Mora, R., Swings, J. \& other authors (2002). Report of the ad hoc committee for the reevaluation of the species definition in bacteriology. Int J Syst Evol Microbiol 52, 1043-1047.

Thompson, J. D., Gibson, T. J., Plewniak, F., Jeanmougin, F. \& Higgins, D. G. (1997). The CLUSTAL_X windows interface: flexible strategies for multiple sequence alignment aided by quality analysis tools. Nucleic Acids Res 25, 4876-4882.

Ziemke, F., Höfle, M. G., Lalucat, J. \& Rosselló-Mora, R. (1998). Reclassification of Shewanella putrefaciens Owen's genomic group II as Shewanella baltica sp. nov. Int J Syst Bacteriol 48, 179-186. 